\title{
Single crystal X-ray structure of (Z)-1-bromo-1-nitro-2-phenylethene
}

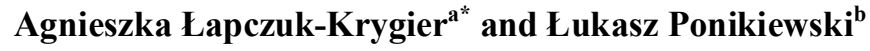

\begin{abstract}
${ }^{a}$ Institute of Organic Chemistry and Technology, Cracow University of Technology, Warszawska St. 24, 31-155 Cracow, Poland
${ }^{b}$ Chemical Faculty, Department of Inorganic Chemistry, Gdansk University of Technology, G. Narutowicza St. 11/12, Pl-80-233 Gdansk, Poland

C H R O N I C L E

Article history:

Received May 6, 2014

Received in revised form

October 02,2014

\section{A B S T R A C T}

The title compound - (Z)-1-bromo-1-nitro-2-phenylethene - was prepared by a three-step reaction. Its structure was confirmed by spectral analysis as well as X-ray crystallography. It was found, that the compound crystallized in the orthorhombic system, space group $\mathrm{Pbca}$, $a=11.5296(6) \AA, b=7.5013(5) \AA, c=19.7187(12) \AA, \alpha=\beta=\gamma=90^{\circ}, Z=8$.
\end{abstract}

Accepted 2 December 2014

Available online

2 December 2014

Keywords:

nitroalkene

X-ray crystal structure

\section{Introduction}

The present work is part of our project on synthesis, structure investigation and property evaluation of conjugated nitroalkenes ${ }^{1,2,3}$. In particular, we decided to shed light on structure of 1-bromo-1-nitro2-phenylethene. This compound is $\mathrm{known}^{4}$, but - unfortunately - complete structural data are not avaiable. In the other hand, title compound is very important from practical point of view. Gemhalonitro functionalized compounds have significant antibacterial activity and the ability to stimulate cell sensitivity and inhibit tissue bleeding processes ${ }^{5}$. Many $\beta$-arylnitroethenes and their derivatives have been documeted to display diverse biological activities including antibacterical ${ }^{6}$, molluscicidal $^{7,8}$ and anticancer ${ }^{9,10,11}$. $\beta$-arylnitroethenes are also used as versatile intermediates in organic syntheses such as selective reductions to diverse functional groups, the Diels-Alder cycloaddition reactions ${ }^{12,13}$, and the Michael addition ${ }^{14}$.

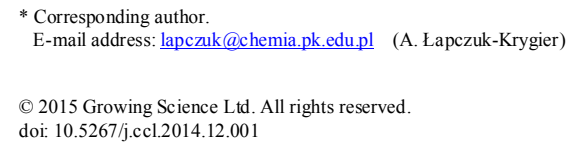




\section{Results and Discussion}

For the preparation of $\beta$-nitrostyrenes halosubstituted in the $\beta$-position we can use of three procedures: (I) via interaction between nitryl halogenides and alkenes, (II) condensation of gemhalonitrocompounds with aldehydes ${ }^{15}$, or (III) via addition of halogenide to the nitrostyrene, with subsequent elimination of hydrogen halide from the halonitro compound ${ }^{4}$. We decided on last strategy (Scheme 1) (see experimental section).

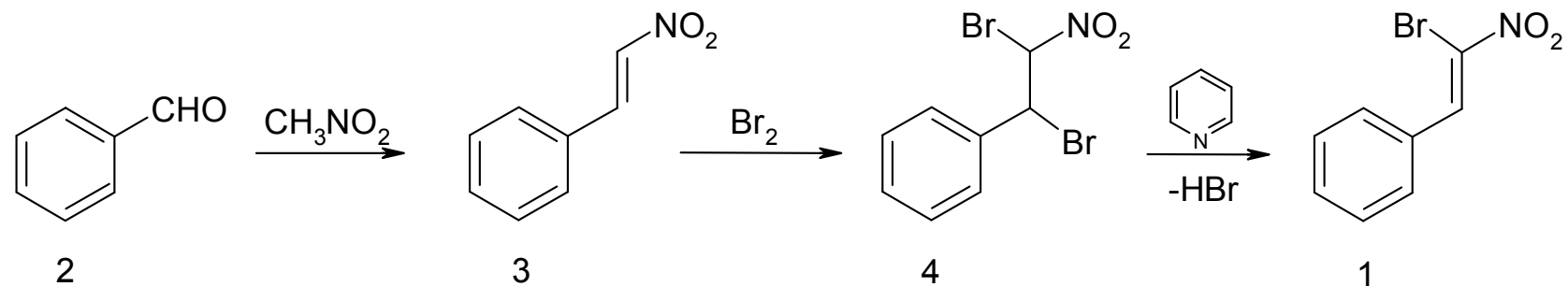

Scheme 1.

\subsection{Crystal structure determination of 1}

The crystal structure of $\mathbf{1}$ is shown in Fig. 1. Experimental diffraction data were collected on a KM4CCD kappa-geometry diffractometer, equipped with a Sapphire2 CCD detector. An enhanced Xray $\mathrm{MoK} \alpha$ radiation source with a graphite monochromator was used. Determination of the unit cells and data collection were carried out at $298 \mathrm{~K}$. Data reduction, absorption correction and space group determination were made using the CRYSALISPRO software package ${ }^{16}$. The structures were solved by direct methods and refined by full-matrix least-squares on $F^{2}$ (all data) using the SHELXL program package $^{17}$.

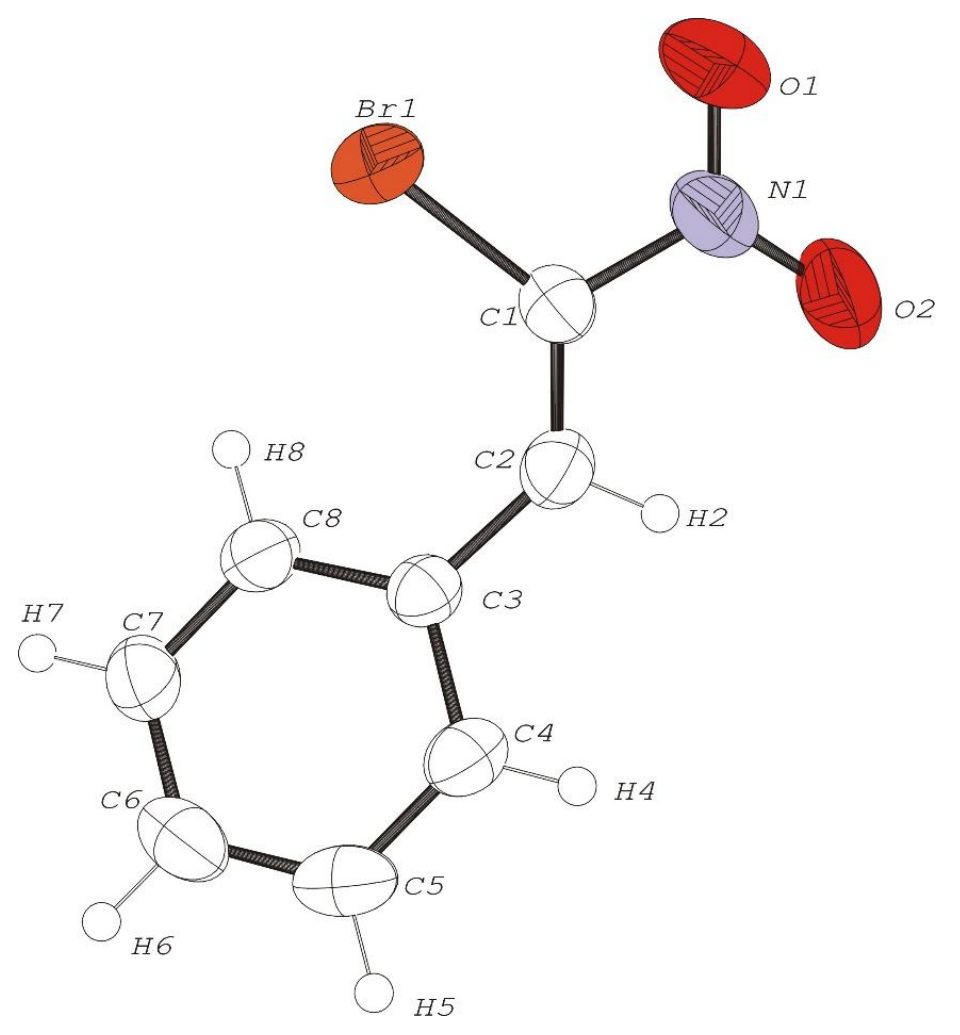

Fig 1. Molecular structure of 1 
Crystallographic data for the structure reported here have been deposited with the Cambridge Crystallographic Data Centre (Deposition No. CCDC-1030430). The data can be obtained free of charge via http://www.ccdc.cam.ac.uk/perl/catreq.cgi (or from the CCDC, 12 Union Road, Cambridge CB2 1EZ, UK; Fax: (+44) 1223-336-033; e-mail: deposit@ccdc.cam. ac.uk).

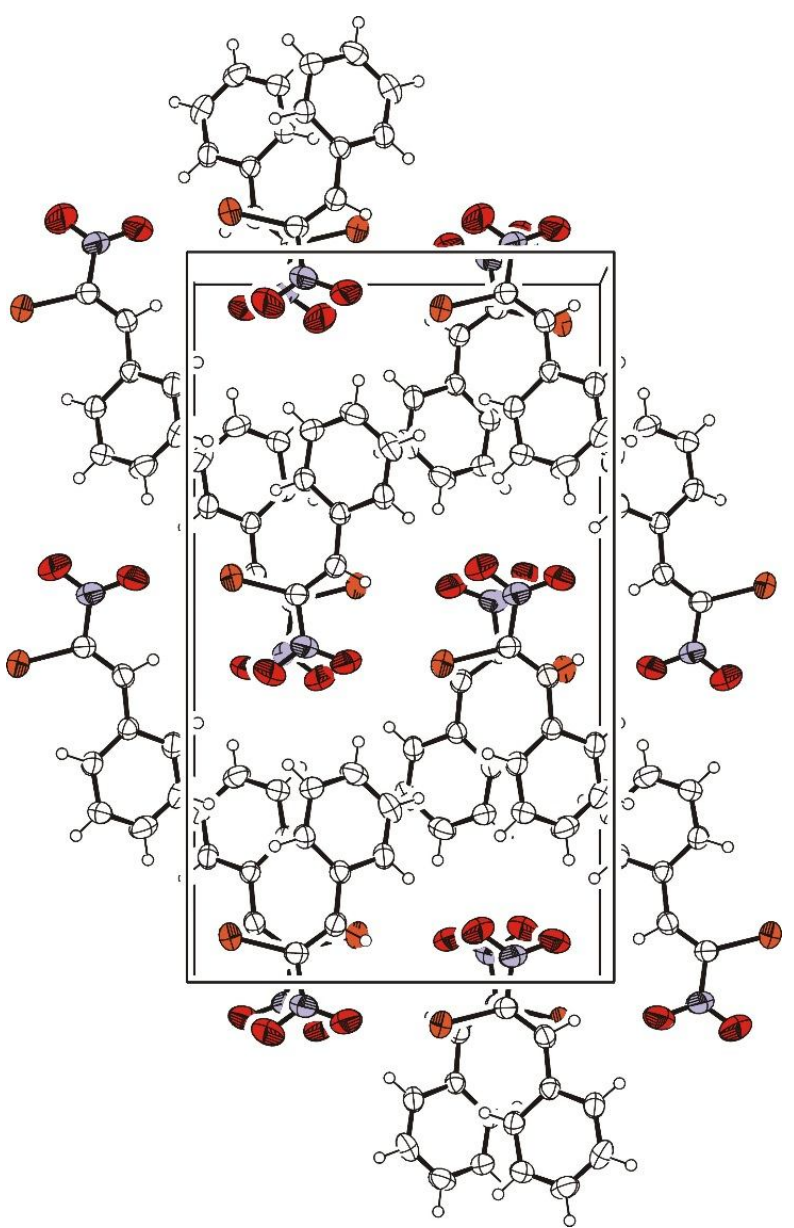

Fig 2. Crystal packing of 1

\subsection{Description of the crystal structure of 1}

The crystal structure of $1\left(\mathrm{C}_{8} \mathrm{H}_{6} \mathrm{BrNO}_{2}\right)$ and its crystal packing are shown in Fig. 1 and Fig. 2, respectively. The selected crystallographic data and experimental details for $\mathbf{1}$ are given in Table 1, selected bond lengths and angles for this compound are shown in Table 2. Initially we decided to shed light on configuration of $\mathbf{1}$. Unfortunately, determination of the geometric isomerism of $\mathbf{1}$ by the NMR spectra is practically impossible due to lack of diagnostic protons. This problem has been successfully resolved by the X-ray crystallography. It was found, that the phenyl group and bromine are on the same side of $\mathrm{C} 1=\mathrm{C} 2$ double bond, whereas the nitro group and hydrogen atom $\mathrm{H} 1$ are on the another side. Thus, the molecule has a $\mathrm{Z}$ configuration. We determined that the dihedral angle between the 1bromoethylene moiety and the nitro group (T1) is equal to $3.00^{\circ}$, whereas the dihedral angle between phenyl and 1-bromoethene moieties (T2) is equal to $28.67^{\circ}$. Therefore the molecule is not planar. In pdimethylamino- $\beta, \beta$-bromonitrostyrene ${ }^{18}$, the closest structurally compound, the $\mathrm{T} 2$ angle is equal to $4.81^{\circ}$. It should be noted also that $\mathrm{C} 1-\mathrm{C} 2$ bond lengths in ethene moiety is equal to $1.332(5) \AA$ and shows typical double-bond character. The crystal structure of $\mathbf{1}$ shows a weak intermolecular interaction between $\mathrm{O} 2$ atom of one molecule and $\mathrm{H} 2$ and $\mathrm{H} 6$ atoms of the two other molecules. 
Table 1. Crystal Data and Experimental Details for 1

\begin{tabular}{llll}
\hline Empirical formula & $\mathrm{C}_{8} \mathrm{H}_{6} \mathrm{BrNO}_{2}$ & Scan type & $\omega-2 \theta$ \\
Formula weight & 228.045 & $\theta$ range & $2.71-28.36$ \\
Crystal color & yellow & Index range & $-14 \leq \mathrm{h} \leq 13$ \\
& & & $-9 \leq \mathrm{k} \leq 7$ \\
& & & $-24 \leq 1 \leq 19$ \\
Crystal system & Orthorhombic & Measured reflections & 2828 \\
Space group & $P b c a$ & Independent reflections & 1678 \\
$\mathrm{Z}$ & 8 & Observed refl. I $\geq 2 \sigma(\mathrm{I})$ & 1195 \\
$\mathrm{~V}, \AA^{3}$ & $1705.41(18)$ & Completeness to $\theta=28.36^{\circ}$ & 99.9 \\
$\mathrm{D}(\mathrm{calc}),{\mathrm{g} . \mathrm{cm}^{-3}}^{-3}$ & 1.776 & Refinement on & $F^{2}$ \\
$\mathrm{a}, \AA$ & $11.5296(6)$ & Final $R$ indices $[I>2 \sigma(I)]$ & 3.12 \\
$\mathrm{~b}, \AA$ & $7.5013(5)$ & R (all data) & 5.22 \\
$\mathrm{c}, \AA$ & $19.7187(12)$ & The goodness of fit on $F^{2}$ & 1.016 \\
$\alpha, \beta, \gamma, \mathrm{deg}$ & 90 & Weighting parameter a/b & $0.047 / 0.866$ \\
$\mu, \mathrm{mm}$ & -1 & Max and min $\Delta \rho\left(\mathrm{e} \AA^{-3}\right)$ & $0.321 /-0.413$ \\
$\mathrm{~F}(000)$ & 4.776 & & \\
\hline
\end{tabular}

Table 2. Selected Bond Lengths and Angles $\left(\AA,^{\circ}\right)$ of 1

\begin{tabular}{llll}
\hline Bond & d & Angles & $\boldsymbol{\omega}$ \\
\hline C4 C5 & $1.378(5)$ & O1 N1 O2 & $122.1(4)$ \\
C3 C4 & $1.402(5)$ & O1 N1 C1 & $119.0(3)$ \\
C8 C3 & $1.399(5)$ & O2 N1 C1 & $118.9(3)$ \\
C7 C8 & $1.378(4)$ & N1 C1 C2 & $118.7(3)$ \\
C6 C7 & $1.376(5)$ & N1 C1 Br1 & $113.3(2)$ \\
C5 C6 & $1.377(5)$ & Br1 C1 C2 & $128.1(3)$ \\
C2 C3 & $1.459(4)$ & C2 C3 C4 & $131.5(3)$ \\
C1 C2 & $1.332(5)$ & C2 C3 C8 & $124.5(3)$ \\
C1 Br1 & $1.866(3)$ & C4 C3 C8 & $117.8(3)$ \\
C1 N1 & $1.479(4)$ & C3 C4 C5 & $121.2(3)$ \\
N1 O1 & $1.209(5)$ & C4 C5 C6 & $119.7(3)$ \\
N1 O2 & $1.229(5)$ & C5 C6 C7 & $120.3(3)$ \\
& & C6 C7 C8 & $120.3(3)$ \\
\hline
\end{tabular}

\section{Experimental}

\subsection{Materials and Methods}

${ }^{1} \mathrm{H}$ NMR spectra were recorded with a Bruker Avance AMX $(300 \mathrm{MHz})$. The spectra were measured in $\mathrm{CDCl}_{3}$ using TMS as the internal standard. Melting point was determined on a Boetius apparatus. Infrared spectra was determined on a Bio-Rad $175 \mathrm{C}$ spectrometer, using $\mathrm{KBr}$ disks. Elemental analysis was performed on a Perkin-Elmer PE-2400 CHN apparatus. All starting materials, reagents and solvents were purchased from commercial sources. Condensation between benzaldehyde and nitromethane as well as addition of bromine to double bond of $\beta$-nitrostyrene were proceed according to known procedure ${ }^{4,19}$.

\subsection{Preparation of 1 (Z)-1-bromo-1-nitro-2-phenylethene}

For preparation of $\mathbf{1}$ in a flask equipped with condenser and dropping funnel placed 84g 1,2dibromo-1-nitro-2-phenylethene and $340 \mathrm{ml}$ of cyclohexane. Mixture was stirred and heated to the reflux solution of $25 \mathrm{ml}$ pyridine in $75 \mathrm{ml}$ cyclohexane was slowly added. Heating was continued by 15 min. The mixture was washed with ether $(400 \mathrm{ml})$ and water $(100 \mathrm{ml})$. Organic layer was washed with 
diluted hydrochloric acid and water, and then dried over $\mathrm{Na}_{2} \mathrm{SO}_{4}$. Solution was concentrated and cooled. The crude product was separated by filtration and recrystallized from glacial acetic acid and than cyclohexane. The yellow needles $(37 \mathrm{~g}, 82 \%)$. were obtained.

\subsection{Physical and Spectral Data}

(Z)-1-bromo-1-nitro-2-phenylethene: $\mathrm{mp} 64-66^{\circ} \mathrm{C}$ (reported: $67-68^{\circ} \mathrm{C}{ }^{4}, 63-64^{\circ} \mathrm{C}{ }^{20}$ ). Anal. Calc. for $\mathrm{C}_{8} \mathrm{H}_{6} \mathrm{BrNO}_{2}: \mathrm{C}, 42.14 ; \mathrm{H}, 2.65 ; \mathrm{N}, 6$,14. Found: $\mathrm{C}, 42.27 ; \mathrm{H}, 2.41 ; \mathrm{N}, 6.18 .{ }^{1} \mathrm{H}-\mathrm{NMR} \delta(\mathrm{ppm}) 7.46-$ 7-58 (3H, m), 7.83-7.95(2H, m), 8,63(1H, s); IR (KBr, $\left.\mathrm{cm}^{-1}\right) 3033(\mathrm{~m}), 1598(\mathrm{~m}), 1530(\mathrm{~s}), 1446(\mathrm{~m})$, 1309 (s), 1285 (s), 1210 (m), 957 (s), 930 (s),764 (s), 689 (m), 503 (m);

\section{Conclusions}

In conclusion, single crystal x-ray structural analysis proved without any doubts geometrical Zconfiguration of 1-bromo-1-nitro-2-phenylethene. However, surprisingly molecule of this compound is not planar.

\section{Acknowledgements}

Financial support from the Polish Ministry of Science and Higher Education (Grant Number C-2/33/2014/DS) are gratefully acknowledged.

\section{References}

1. Łapczuk-Krygier, A., Ponikiewski, Ł., Jasiński, R. (2014) The Crystal Structure of (1RS,4RS,5RS,6SR)-5-cyano-5-nitro-6-phenyl-bicyclo[2.2.1]hept-2-ene. Crystallogr. Reports 59, 961-963.

2. Jasiński, R. (2012) Exploration of regiospecificity phenomenon in [2+3] cycloaddition reactions between arylnitrones and trans-substituted nitroethenes on the basis of the reactivity indices theory. Current Chem. Lett. 1, 157-162.

3. R. Jasiński, M. Kubik, A. Łapczuk-Krygier, A. Kącka, E. Dresler, and A. Boguszewska-Czubara (2014) An experimental and theoretical study of the hetero Diels-Alder reactions between (E)-2aryl-1-cyano-1-nitroethenes and ethyl vinyl ether: one-step or zwitterionic, two-step mechanism? React. Kinet. Mech. Catal.. doi:10.1007/s11144-014-0753-8

4. Parham, W., Bleasdale, J. (1951) The Condensation of Diazo Compounds with Nitroölefins. II. 3Bromo-and 3-Nitropyrazoles. J. Am. Chem. Soc. 73, 4664-4666.

5. R. Jasiński, M. Mikulska, O. Koifman, and A. Barański (2013) Conjugated nitroalkenes in cycloaddition reactions $18^{*}$. Regio- and stereoselectivity of $(2+3)$ cycloaddition reactions between gem-chloronitroethene and (Z)-C,N-diarylnitrones. Chem. Heterocycl. Compd. 49, 1188-1194.

6. A. G. Clark, B. Croshaw, B. E. Leggetter, and D. F. Spooner (1974) "Synthesis and Antimicrobial Activity of Aliphatic Nitro Compounds," J. Med. Chem., 17, 9, 977-981.

7. Schales, O., Graefe, H. A. (1952) Arylnitroalkenes: A New Group of Antibacterial Agents1. J. Am. Chem. Soc. 74, 4486-4490.

8. N. Milhazes, R. Calheiros, M. P. M. Marques, J. Garrido, M. N. D. S. Cordeiro, C. Rodrigues, S. Quinteira, C. Novais, L. Peixe, and F. Borges (2006) Beta-nitrostyrene derivatives as potential antibacterial agents: a structure-property-activity relationship study. Bioorg. Med. Chem. 14, 4078-4088.

9. P. Cheng, Z.-Y. Jiang, R.-R. Wang, X.-M. Zhang, Q. Wang, Y.-T. Zheng, J. Zhou, and J.-J. Chen (2007) Synthesis and biological evaluation of N-acetyl-beta-aryl-1,2-didehydroethylamines as new HIV-1 RT inhibitors in vitro. Bioorg. Med. Chem. Lett. 17, 4476-4480. 
10. S. Kaap, I. Quentin, D. Tamiru, M. Shaheen, K. Eger, and H. J. Steinfelder (2003) Structure activity analysis of the pro-apoptotic, antitumor effect of nitrostyrene adducts and related compounds. Biochem. Pharmacol. 65, 603-610.

11. Kim, J. H. (2003) Potent Inhibition of Human Telomerase by Nitrostyrene Derivatives. Mol. Pharmacol. 63, 1117-1124.

12. Jasiński, R., Koifman, O., Barański, A. (2011) A B3LYP/6-31G(d) study of Diels-Alder reactions between cyclopentadiene and (E)-2-arylnitroethenes. Cent. Eur. J. Chem. 9, 1008-1018.

13. Jasiński, R., Kwiatkowska, M., Barański, A. (2011) Stereoselectivity and kinetics of [4 +2$]$ cycloaddition reaction of cyclopentadiene to para-substituted E-2-arylnitroethenes. J. Phys. Org. Chem. 24, 843-853.

14. M. Zhang, P. Hu, J. Zhou, G. Wu, S. Huang, and W. Su (2013) Pd-catalyzed multidehydrogenative cross-coupling between (hetero)arenes and nitroethane to construct $\beta$-aryl nitroethylenes. Org. Lett. 15, 1718-1721.

15. Bláha, I., Lešetický, L. (1986) Preparation and Z-E isomerization of substituted nitrostyrenes. Collect. Czechoslov. Chem. Commun. 51, 1094-1099.

16. Program CRYSALISPRO Version 1.171 (2008) Oxford Diffraction, Abingdon, England.

17. Sheldrick, G. M. (2008) A short history of SHELX. Acta Crystallogr. A. 64, 112-122.

18. L. A. Chetkina, E. G. Popova, and G. A. Gol'der (1975) "X-ray diffraction investigation of pdimethylamino-B,B-bromonitrostyrene," J. Struct. Chem., 15, 5, 768-771.

19. Vogel, A. I. (1956) A textbook of practical organic chemistry, 3rd Ed., Longman, London.

20. Ganesh, M., Namboothiri, I. N. N. (2007) Stereospecific approach to $\alpha, \beta$-disubstituted nitroalkenes via coupling of $\alpha$-bromonitroalkenes with boronic acids and terminal acetylenes. Tetrahedron 63, 11973-11983. 